Pacific Journal of Mathematics

THE COMMUTATOR AND SOLVABILITY IN A GENERALIZED
ORTHOMODULAR LATTICE 


\title{
THE COMMUTATOR AND SOLVABILITY IN A GENERALIZED ORTHOMODULAR LATTICE
}

\author{
E. L. Marsden, JR.
}

In this paper we prove in a generalized orthomodular lattice the analog of the following theorem from group theory. For $a$ and $b$ members of a group $G$, let $a b a^{-1} b^{-1}$ be the commutator of $a$ and $b$. The set of commutators in $G$ generates a normal subgroup $H$ of $G$ possessing these properties: $G / H$ is Abelian. Moreover, if $K$ is any normal subgroup of $G$ for which $G / K$ is Abelian, then $K \supseteqq H$. Continuing the analogy with group theory, we determine a solvability condition on generalized orthomodular lattices.

An orhomodular lattice is a lattice $L$ with 0 and 1 and with an orthocomplementation': $L \rightarrow L$ satisfying the orthomodular identity: for $e \leqq f$ in $L, f=e \vee\left(f \wedge e^{\prime}\right)$. Throughout this paper $L$ shall denote an orthomodular lattice. For $f \in L$ the Sasaki projection determined by $f \phi_{f}: L \rightarrow L$ by $e \phi_{f}=\left(e \vee f^{\prime}\right) \wedge f$. We say $e$ commutes with $f$, ecf, when $e \phi_{f}=e \wedge f$. Basic properties of orthomodular lattices and of their coordinatizing Baer *-semigroups are contained in $[1,2]$.

A lattice ideal $I$ in $L$ is called a $p$-ideal if and only if $e \in I$ and $f \in L$ imply $\mathrm{e} \phi_{f} \in I$. Theorem 6 , which concerns $p$-ideals in generalized orthomodular lattices, indicates the significance of $p$-ideals in orthomodular lattices.

2. The commutator. For elements $e$ and $f$ of the orthomodular lattice $L$, we define the commutator of $e$ and $f$ by

$$
[e, f]=(e \vee f) \wedge\left(e \vee f^{\prime}\right) \wedge\left(e^{\prime} \vee f\right) \wedge\left(e^{\prime} \vee f^{\prime}\right) .
$$

It is easily shown that ecf if and only if $[e, f]=0$, and that $[e, f]=$ $\left[e, f^{\prime}\right]=\left[e^{\prime}, f\right]=\left[e^{\prime}, f^{\prime}\right]$.

Theorem 1. Let $R$ be a Baer *-ring, and let $P^{\prime}(R)$ denote the orthomodular lattice of closed projections in $R$. Then for

$$
e, f \in P^{\prime}(R),(e f-f e)^{\prime \prime}=[e, f] .
$$

In proving the theorem, we shall use the following computation.

Lemma 2. $[e, f]=\left(f^{\prime} e f\right)^{\prime \prime} \vee\left(e^{\prime} f e\right)^{\prime \prime}$.

Proof. $\left(f^{\prime} e f\right)^{\prime \prime}=\left(\left(f^{\prime} e\right)^{\prime \prime} f\right)^{\prime \prime}=f^{\prime} \phi_{e} \phi_{f}=\left\{\left[\left(f^{\prime} \vee e^{\prime}\right) \wedge e\right] \vee f^{\prime}\right\} \wedge f=$ 
$\left(f^{\prime} \vee e^{\prime}\right) \wedge\left(e \vee f^{\prime}\right) \wedge f$, where the last equality holds by the FoulisHolland theorem [2]-observe that $\left(f^{\prime} \vee e^{\prime}\right) c e$, and $\left(f^{\prime} \vee e^{\prime}\right) c f^{\prime}$. Similarly, $\left(e^{\prime} f e\right)^{\prime \prime}=\left(f^{\prime} \vee e^{\prime}\right) \wedge\left(e^{\prime} \vee f\right) \wedge e$. The following expression is simplified by repeated applications of the Foulis-Holland theorem. We have

$$
\begin{aligned}
& \left(f^{\prime} e f\right)^{\prime \prime} \vee\left(e^{\prime} f e\right)^{\prime \prime} \\
= & {\left[\left(f^{\prime} \vee e^{\prime}\right) \wedge\left(e \vee f^{\prime}\right) \wedge f\right] \vee\left[\left(f^{\prime} \vee e^{\prime}\right) \wedge\left(e^{\prime} \vee f\right) \wedge e\right] } \\
& \quad\left(f^{\prime} \vee e^{\prime}\right) c\left(e \vee f^{\prime}\right) \wedge f,\left(e^{\prime} \vee f\right) \wedge e \\
= & \left(f^{\prime} \vee e^{\prime}\right) \wedge\left\{\left[\left(e \vee f^{\prime}\right) \wedge f\right] \vee\left[\left(e^{\prime} \vee f\right) \wedge e\right]\right\} \\
& \quad\left(e^{\prime} \vee f\right) c\left(e \vee f^{\prime}\right) \wedge f, e \\
= & \left(f^{\prime} \vee e^{\prime}\right) \wedge\left[\left(e^{\prime} \vee f\right) \wedge\left\{\left[\left(e \vee f^{\prime}\right) \wedge f\right] \vee e\right\}\right] \\
& \quad\left(e \vee f^{\prime}\right) c f, e \\
= & \left(f^{\prime} \vee e^{\prime}\right) \wedge\left(e^{\prime} \vee f\right) \wedge\left(e \vee f^{\prime}\right) \wedge(f \vee e)=[e, f] .
\end{aligned}
$$

Proof of theorem. The element (ef-fe $)^{\prime \prime}$ is the smallest closed projection serving as a right identity for $(e f-f e)$. Equivalently, $(e f-f e)^{\prime}$ is the greatest closed projection which serves as a right annihilator for $e f-f e$. Thus for $k \in P^{\prime}(R), k \leqq(e f-f e)^{\prime}$ if and only if $e f k=f e k$.

Suppose that for some $k \in P^{\prime}(R)$, efk $=f e k$. Then $f^{\prime} e f k=f^{\prime} f e k=$ 0 implies that $k=\left(f^{\prime} e f\right)^{\prime} k$, or $k \leqq\left(f^{\prime} e f\right)^{\prime}$. Similarly $k \leqq\left(e^{\prime} f e\right)^{\prime}$, and hence $k \leqq\left(e^{\prime} f e\right)^{\prime} \wedge\left(f^{\prime} e f\right)^{\prime}=[e, f]^{\prime}$. Also, $(e f)[e, f]^{\prime}=e\left(f[e, f]^{\prime}\right)=$ $e\left(f \wedge[e, f]^{\prime}\right)=e\left(f \wedge\left[(e \wedge f) \vee\left(e \wedge f^{\prime}\right) \vee\left(e^{\prime} \wedge f\right) \vee\left(e^{\prime} \wedge f^{\prime}\right)\right]\right)=$ $e\left[(e \wedge f) \vee\left(e^{\prime} \wedge f\right)\right]=e \wedge\left[(e \wedge f) \vee\left(e^{\prime} \wedge f\right)\right]=e \wedge f=f e[e, f]^{\prime}$. Moreover, for $k \leqq[e, f]^{\prime}$, then $k=[e, f]^{\prime} k$ and $e f k=e f[e, f]^{\prime} k=$ $f e[e, f]^{\prime} k=f e k$. Thus we have shown that $e f k=f e k$ if and only if $k \leqq[e, f]^{\prime}$. Therefore $(e f-f e)^{\prime}=[e, f]^{\prime}$ and $(e f-f e)^{\prime \prime}=[e, f]$.

Lemma 3. For $e, f \in L, f \phi_{e} \leqq f \vee[f, e]$.

Proof. By the Foulis-Holland theorem,

$$
f \vee\left[(f \vee e) \wedge\left(f \vee e^{\prime}\right) \wedge\left(f^{\prime} \vee e\right) \wedge\left(f^{\prime} \vee e^{\prime}\right)\right]=(f \vee e) \wedge\left(f \vee e^{\prime}\right)
$$

Lemma 4. Let $L$ and $X$ be orthomodular lattices.

(i) For an ortho-homomorphism $\phi: L \rightarrow X$ and c a commutator in $L, c \phi$ is a commutator in $X$.

(ii) For an ortho-epimorphism $\phi: L \rightarrow X$ and $x$ a commutator in $X, x=c \phi$ where $c$ is a commutator in $L$.

(iii) $X$ is Boolean if and only if 0 is the only commutator in $X$.

Proof. Ortho-homomorphisms preserve suprema, infima, and orthocomplements. 
THEOREM 5. Let $L$ be an orthomodular lattice, and let $J$ be the ideal generated by the commutators in $L$. Then $J$ is a p-ideal, and $L / J$ is Boolean. Moreover, if $I$ is any p-ideal for which $L / I$ is Boolean, then $I \supseteqq J$.

Proof. Let $J$ be the ideal generated by the commutators in $L$, i.e.,

$$
J=\left\{y \in L \mid \text { for some commutators } c_{1}, \cdots, c_{n} \text { in } L, y \leqq \bigvee_{i=1}^{n} c_{i}\right\} .
$$

We claim that $J$ is a $p$-ideal. Take any $x \in L$ and $y \leqq \bigvee_{i=1}^{n} c_{i}$ a finite join of commutators in $L$. Then by Lemma $3, y \phi_{x} \leqq\left(\mathbf{V}_{i=1}^{n} c_{i}\right) \phi_{x}=$ $\bigvee_{i=1}^{n}\left(c_{i} \phi_{x}\right) \leqq \bigvee_{i=1}^{n}\left(c_{i} \vee\left[c_{i}, x\right]\right)$, and hence $y \phi_{x} \in J$.

To show that $L / J$ is Boolean, use the natural ortho-epimorphism $\phi: L \rightarrow L / J$, and apply Lemma 4 (ii). A second application of Lemma 4 completes the proof of the theorem.

3. Solvability in a generalized orthomodular lattice. At this point it is impossible to mimic the solvability conditions of group theory [4]. The difficulty is that the $p$-ideals in orthomodular lattices need not be orthomodular lattices. In fact, a $p$-ideal $I$ of $L$ contains a greatest element $d$ if and only if $I=L(0, d)$, where $d$ is central in $L$. In order to generalize both orthomodular lattices and $p$-ideals we make the following

DEFINITION. $G$ is a generalized orthomodular lattice (GOML) if and only if

(i) $0 \in G$,

(ii) for every nonzero $a \in G, G(0, a)=\{x \in G \mid 0 \leqq x \leqq a\}$ is an orthomodular lattice, and

(iii) for $x \leqq a \leqq b$ in $G$, and for $a-x$ and $b-x$ the orthocomplements of $x$ in $G(0, a)$ and $G(0, b)$ respectively, $a-x=(b-x) \wedge a$.

M. F. Janowitz [5] has shown that every GOML $G$ can be embedded as a $p$-ideal in an orthomodular lattice $L$. If $G$ is not already an orthomodular lattice then $G$ is embedded as a prime ideal in $L$, i.e., for $a \in L$ either $a \in G$ or $a^{\prime} \in G$. Let $G$ be a GOML, and let $G \leqq L$ be the Janowitz embedding. For any $e, f \in L$, since $G$ is prime in $L$, then $[e, f] \in G$. Thus the $p$-ideal generated by the cummutators in $L$ is a subset of $G$. The following theorem clarifies this. For elements $e, f \in G$ we define the generalized Sasaki projection by $e \Psi_{f}=\{e \vee[(e \vee f)-f]\} \wedge f$, the Sasaki projection in $G(0, e \vee f)$. An ideal $I$ of $G$ is called a $p$-ideal of $G$ when $I$ is closed under all generalized Sasaki projections. For elements $e, f \in G$ we say that $e$ is perspective to $f$ via $t$, written $e \sim{ }_{p} f$, if and only if for some 
$t \in G, e \vee t=f \vee t$ and $e \wedge t=f \wedge t=0$.

TheoRem 6. Let $I$ be an ideal of $G$, and let $G \leqq L$ be the Janowitz embedding. These conditions are equivalent.

(i) For $e \in I, f \in G$ and $e \sim{ }_{p} f$, then $f \in I$.

(ii) $I$ is a p-ideal of $G$.

(iii) $I$ is a p-ideal of $L$.

(iv) For $e \in I, f \in L$ and $e \sim{ }_{p} f$, then $f \in I$.

(v) $I$ is the kernel of a (unique) congruence on $L$.

(vi) $I$ is the kernel of a (unique) congruence on $G$.

Proof. (i) $\Longrightarrow$ (ii). Let $e \in I$ and $f \in G . \quad$ A computation shows that $e \Psi_{f} \sim{ }_{p} f \Psi_{e}$ via $(e \vee f)-e \Psi_{f}$. Since $f \Psi_{e} \leqq e$, then $f \Psi_{e} \in I$, and by (i) $e \Psi_{f} \in I$.

(ii) $\Rightarrow$ (iii). Let $e \in I$ and $f \in L$. If $f \in G$, we are finished. Otherwise, $f^{\prime} \in G$ and it follows that $e \vee f^{\prime} \in G$ and $e \phi_{f}=\left(e \vee f^{\prime}\right) \wedge f \in G$. By (ii), $e \Psi_{e \phi_{f}} \in I$. But

$$
\begin{aligned}
e \Psi_{e \phi_{f}} & =\left[e \vee\left[\left(e \vee e \phi_{f}\right)-e \phi_{f}\right]\right\} \wedge e \phi_{f}=\left\{e \vee\left[\left(e \phi_{f}\right)^{\prime} \wedge\left(e \vee e \phi_{f}\right)\right]\right\} \wedge e \phi_{f} \\
& =\left[e \vee\left(e \phi_{f}\right)^{\prime}\right] \wedge\left[e \vee e \phi_{f}\right] \wedge e \phi_{f} \\
& =\left[e \vee\left(e^{\prime} \wedge f\right) \vee f^{\prime}\right] \wedge e \phi_{f}=e \phi_{f} .
\end{aligned}
$$

(iii) $\Leftrightarrow$ (iv) $\Leftrightarrow$ (v) are well known [3].

(v) $\Rightarrow$ (vi). The restriction of the congruence on $L$ to $G$ is a congruence. Notice that the congruence preserves relative orthocomplements. The uniqueness stems the fact in any relatively complemented lattice with 0 , every ideal is the kernel of at most one congruence [3].

(vi) $\Rightarrow$ (i). Suppose that $\theta$ is a congruence on $G$ with ker $\theta=I$. Let $e \in I$ and $f \in G$ with $e \sim{ }_{p} f$ via $t \in G$. The $e \theta 0$ implies $e \vee t \theta t$, or $\mathrm{f} \vee t \theta t$. It follows that $f=(f \vee t) \wedge f \theta t \wedge f=0$. Hence $f \in I$.

The Janowitz embedding and Theorem 6 furnish an immediate generalization of Theorem 5 .

THEOREM 7. Let $G$ be a GOML, and let $J$ be the commutator p-ideal in $G$. Then $G / J$ is distributive. Moreover, if $I$ is a p-ideal of $G$ for which $G / I$ is distributive, then $I \supseteqq J$.

We are now in a position to discuss solvability of GOML. Let $G$ be a GOML, let $G_{1}$ be the $p$-ideal generated by the commutators in $G$, and for $n>1$ let $G_{n}$ be the $p$-ideal generated by the commutators in $G_{n-1}$. A GOML $G$ will be called solvable if and only if for some $n G_{n}=\{0\}$.

LEMMA 8. Let $J$ be a p-ideal in a GOML $G$, and let $I$ be a $p$-ideal in $J$. Then $I$ is a p-ideal in $G$. 
Proof. We shall show for $e \in I, f \in G$ that $e \Psi_{f} \in I$. Since $e \in J$, a $p$-ideal in $G$, then $e \Psi_{f} \in J$. Therefore $\mathrm{e} \Psi_{e \Psi_{f}} \in I$. A computation shows that $e \Psi_{e \Psi_{f}}=e \Psi_{f}$.

THEOREM 9. Let $G$ be a GOML. For $G$ to be solvable it is a necessary and sufficient condition that $G$ be distributive.

Proof. Theorem 7 proves the sufficiency. We shall prove the necessity by showing that $G_{2}=G_{1}$ and hence that $G_{n}=G_{1}$ for all positive integers $n$.

Let $G \leqq L$ be the Janowitz embedding, and let ' be the orthocomplementation of $L$. For elements $e, f \in G$, set $c=\left(e^{\prime} \vee f^{\prime}\right) \wedge\left(e^{\prime} \vee f\right) \wedge e$ and $d=\left(f^{\prime} \vee e^{\prime}\right) \wedge\left(f^{\prime} \vee e\right) \wedge f$. Then $c \vee d=[e, f]$ by the computation of Lemma 2. Moreover,

$$
\begin{aligned}
& c \vee d^{\prime} \\
= & {\left[\left(e^{\prime} \vee f^{\prime}\right) \wedge\left(e^{\prime} \vee f\right) \wedge e\right] \vee(e \wedge f) \vee\left(f \wedge e^{\prime}\right) \vee f^{\prime} } \\
& \quad(e \wedge f) c\left(e^{\prime} \vee f^{\prime}\right),\left(e^{\prime} \vee f\right), e \\
= & {\left[\left(e^{\prime} \vee f\right) \wedge e\right] \vee\left(f \wedge e^{\prime}\right) \vee f^{\prime} } \\
& \quad\left(e^{\prime} \vee f\right) c e, f^{\prime} \\
= & \left(e \vee f^{\prime}\right) \vee\left(f \wedge e^{\prime}\right)=1 .
\end{aligned}
$$

Similarly $c^{\prime} \vee d=1$. Also $c^{\prime} \vee d^{\prime} \geqq(e \wedge f) \vee e^{\prime} \vee f^{\prime}=1$

We have shown for any $e, f \in G$ and for $c, d$ as above that $[e, f]=[c, d]=c \vee d$. Here $c, d \leqq[c, d]$ imply that $c, d \in G_{1}$, and thus $[e, f]=[c, d] \in G_{2}$. This completes the proof that $G_{1}=G_{2}$.

\section{REFERENCES}

1. D. J. Foulis, Baer *-semigroups, Proc. Amer. Math. Soc. 11 (1960), 648-654.

2. - A note on orthomodular lattices, Portugal Math. 21 (1962), 65-72.

3. - Orthomodular lattices, mimeographed notes, University of Florida, 1963.

4. M. Hall, Jr., Theory of groups, Macmillan, New York, 1959.

5. M. F. Janowitz, A note on generalized orthomodular lattices, J. of Natural Sciences and Math. 8 (1968), 89-94.

Received November 27, 1968. Many of the results in this paper are from the author's doctoral dissertation written under the direction of Professor D. J. Foulis.

UNIVERSITy OF MASSACHUSETTS, AND

Kansas State University 



\section{PACIFIC JOURNAL OF MATHEMATICS}

\section{EDITORS}

H. SAMelson

Stanford University

Stanford, California 94305

\section{Richard PIERCE}

University of Washington

Seattle, Washington 98105
J. DugundjI

Department of Mathematics

University of Southern California

Los Angeles, California 90007

BASIL GoRDON*

University of California

Los Angeles, California 90024

\section{ASSOCIATE EDITORS}
E. F. BECKENBACH
B. H. NeumanN
F. WOLE
K. YosHIDA

\section{SUPPORTING INSTITUTIONS}

UNIVERSITY OF BRITISH COLUMBIA

CALIFORNIA INSTITUTE OF TECHNOLOGY

UNIVERSITY OF CALIFORNIA

MONTANA STATE UNIVERSITY

UNIVERSITY OF NEVADA

NEW MEXICO STATE UNIVERSITY

OREGON STATE UNIVERSITY

UNIVERSITY OF OREGON

OSAKA UNIVERSITY

UNIVERSITY OF SOUTHERN CALIFORNIA

\author{
STANFORD UNIVERSITY \\ UNIVERSITY OF TOKYO \\ UNIVERSITY OF UTAH \\ WASHINGTON STATE UNIVERSITY \\ UNIVERSITY OF WASHINGTON \\ * * * * \\ AMERICAN MATHEMATICAL SOCIETY \\ CHEVRON RESEARCH CORPORATION \\ TRW SYSTEMS \\ NAVAL WEAPONS CENTER
}

The Supporting Institutions listed above contribute to the cost of publication of this Journal, but they are not owners or publishers and have no responsibility for its content or policies.

Mathematical papers intended for publication in the Pacific Journal of Mathematics should be in typed form or offset-reproduced, (not dittoed), double spaced with large margins. Underline Greek letters in red, German in green, and script in blue. The first paragraph or two must be capable of being used separately as a synopsis of the entire paper. The editorial "we" must not be used in the synopsis, and items of the bibliography should not be cited there unless absolutely necessary, in which case they must be identified by author and Journal, rather than by item number. Manuscripts, in duplicate if possible, may be sent to any one of the four editors. Please classify according to the scheme of Math. Rev. 36, 1539-1546. All other communications to the editors should be addressed to the managing editor, Richard Arens, University of California, Los Angeles, California, 90024.

50 reprints are provided free for each article; additional copies may be obtained at cost in multiples of 50 .

The Pacific Journal of Mathematics is published monthly. Effective with Volume 16 the price per volume (3 numbers) is $\$ 8.00$; single issues, $\$ 3.00$. Special price for current issues to individual faculty members of supporting institutions and to individual members of the American Mathematical Society: $\$ 4.00$ per volume; single issues $\$ 1.50$. Back numbers are available.

Subscriptions, orders for back numbers, and changes of address should be sent to Pacific Journal of Mathematics, 103 Highland Boulevard, Berkeley, California, 94708.

PUBLISHED BY PACIFIC JOURNAL OF MATHEMATICS, A NON-PROFIT CORPORATION

Printed at Kokusai Bunken Insatsusha (International Academic Printing Co., Ltd.), 7-17, Fujimi 2-chome, Chiyoda-ku, Tokyo, Japan.

* Acting Managing Editor. 


\section{Pacific Journal of Mathematics}

\section{Vol. 33, No. $2 \quad$ April, 1970}

Raymond Balbes and Alfred Horn, Projective distributive lattices ....... 273

John Findley Berglund, On extending almost periodic functions ......... 281

Günter Krause, Admissible modules and a characterization of reduced left

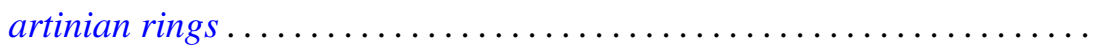

Edward Milton Landesman and Alan Cecil Lazer, Linear eigenvalues and a nonlinear boundary value problem ....................... 311

Anthony To-Ming Lau, Extremely amenable algebras ............... 329

Aldo Joram Lazar, Sections and subsets of simplexes .............. 337

Vincent Mancuso, Mesocompactness and related properties ............. 345

Edwin Leroy Marsden, Jr., The commutator and solvability in a generalized orthomodular lattice .................................. 357

Shozo Matsuura, Bergman kernel functions and the three types of canonical domains.......................................... 363

S. Mukhoti, Theorems on Cesàro summability of series .............. 385

Ngô Van Quê, Classes de Chern et théorème de Gauss-Bonnet ........... 393

Ralph Tyrrell Rockafellar, Generalized Hamiltonian equations for convex problems of Lagrange ................................ 411

Ken iti Sato, On dispersive operators in Banach lattices ............. 429

Charles Andrew Swanson, Comparison theorems for elliptic differential

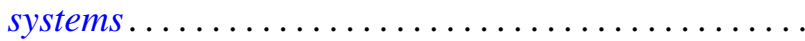

John Griggs Thompson, Nonsolvable finite groups all of whose local subgroups are solvable. II

David J. Winter, Cartan subalgebras of a Lie algebra and its ideals ... 